\title{
Oxygen-by-Sulfur Substitution in $\mathrm{CH}_{3} \mathrm{OCH}_{2} \mathrm{CH}_{2} \mathrm{OH}$ : An ab Initio Comparative Study of Conformational Effects and Intramolecular Interactions
}

\author{
Francisco P. S. C. Gil, ${ }^{\dagger}$ A. M. Amorim da Costa, ${ }^{\ddagger}$ and J. J. C. Teixeira-Dias, ${ }^{*}$ \\ Molecular Physical Chemistry Research Group, Faculty of Sciences and Technology, and Department of \\ Physics, University of Coimbra, P-3049 Coimbra, Portugal
}

Received: June 2, 1995; In Final Form: August 9, $1995^{\otimes}$

Conformational energies, structural parameters and vibrational frequencies for the $\mathrm{tgg}^{\prime}, \mathrm{ggg}^{\prime}$, ttg, and ttt conformers of $\mathrm{CH}_{3} \mathrm{XCH}_{2} \mathrm{CH}_{2} \mathrm{YH}(\mathrm{X}, \mathrm{Y}=\mathrm{O}, \mathrm{S})$ have been determined by $\mathrm{MO}$ ab initio calculations at the MP2/6-31G* level. The results show that the relative strength of the intramolecular X $\cdots H Y$ interaction in $\operatorname{tgg}^{\prime}$ and ggg' conformers diminishes gradually along the series of molecules $(\mathrm{O}, \mathrm{O}) \rightarrow(\mathrm{O}, \mathrm{S}) \rightarrow(\mathrm{S}, \mathrm{O}) \rightarrow$ $(\mathrm{S}, \mathrm{S})$, as the $\mathrm{X} \cdot \mathrm{HY}$ contact distance increases by ca. $2 \times 10 \mathrm{pm}$ for each of these substitutions. For the $(\mathrm{O}, \mathrm{O})$ and $(\mathrm{O}, \mathrm{S})$ molecules, the $\mathrm{CX}-\mathrm{CC}$ trans form is favored over the gauche arrangement, whereas for the $(\mathrm{S}, \mathrm{O})$ and $(\mathrm{S}, \mathrm{S})$ molecules, the gauche conformation is more stable. In addition, the oxygen-by-sulfur substitution in the $\mathrm{YH}$ bond increases the relative stability of the $\mathrm{CC}-\mathrm{YH}$ gauche form with respect to the trans arrangement. In turn, gauche,gauche' arrangements for the $\mathrm{XC}-\mathrm{CY}$ and $\mathrm{CC}-\mathrm{YH}$ axes, respectively, lead to closing of intramolecular rings through $\mathrm{X} \cdot \cdots \mathrm{HY}$ attractive interactions, hence contributing to improve the stability of the conformations with those dihedral arrangements.

\section{Introduction}

Among the most relevant conformers of 2-methoxyethanol $\left(\mathrm{CH}_{3} \mathrm{O}-\mathrm{CH}_{2}-\mathrm{CH}_{2}-\mathrm{OH}: \operatorname{tgg}^{\prime}, \mathrm{ggg}^{\prime}, \mathrm{ttg}\right.$, and ttt), tgg' and ggg' are more stable than ttg and ttt, and tgg' is $6-7 \mathrm{~kJ} \mathrm{~mol}^{-1}$ more stable than ggg $^{\prime \prime}$ The relative stability of gauche and gauche' arrangements in the second and third dihedral angles, $\mathrm{COC}^{\underline{g}} \mathrm{C} \stackrel{g^{\prime}}{\mathrm{O}} \mathrm{OH}$, with respect to their tg and $t \mathrm{t}$ counterparts results mainly from the formation of five membered intramolecular rings due to $\mathrm{O} \cdot \mathrm{H}_{\mathrm{H}}-\mathrm{O}$ hydrogen bonds in the tgg' and

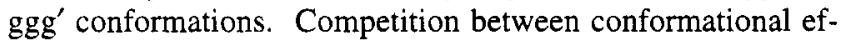
fects and intramolecular hydrogen-bonding interactions gives rise to interesting structural and vibrational features. While a number of studies of these effects have been carried out in our laboratory, ${ }^{2,3}$ further understanding of the interplay between conformational effects and intramolecular hydrogen-bonding interactions requires the possibility of varying those effects in a systematic way and simultaneously modulating the $\mathrm{X} \cdot \cdots \mathrm{HY}$ interactions. To this end, oxygen-by-sulfur substitutions in $\mathrm{CH}_{3-}$ $\mathrm{OCH}_{2} \mathrm{CH}_{2} \mathrm{OH}$ were considered, and calculations at the MP2/ 6-31G* level were carried out using the Gaussian 92 program system. ${ }^{4}$ Fully optimized geometries of the four abovementioned relevant conformations of $\mathrm{CH}_{3} \mathrm{XCH}_{2} \mathrm{CH}_{2} \mathrm{YH}$ (X, Y $=\mathrm{O}, \mathrm{S})$ are identified by a letter acronym which specifies the dihedral arrangements from left to right in $\mathrm{CX}-\mathrm{a} C \stackrel{\mathrm{b}}{\mathrm{C}} \mathrm{c}-\mathrm{YH}(\mathrm{t}$, $\mathrm{g}$, and $\mathrm{g}^{\prime}$ designate trans, gauche, and gauche' conformations, respectively). The absolute errors in bond lengths and bond angles with respect to the equilibrium geometrical parameters are less than $1 \mathrm{pm}$ and $0.1,^{\circ}$ respectively, and the stopping criterion for the SCF iterative process required a density matrix convergence of less than $10^{-8}$. Conformational energy differences, structural parameters, normal modes of vibration, and vibrational frequencies (calculated with the ab initio derived force fields) are herein analyzed and discussed.

\footnotetext{
+ Department of Physics.

¥ Molecular Physical Chemistry Research Group.

${ }^{\otimes}$ Abstract published in Advance ACS Abstracts, October 15, 1995.
}

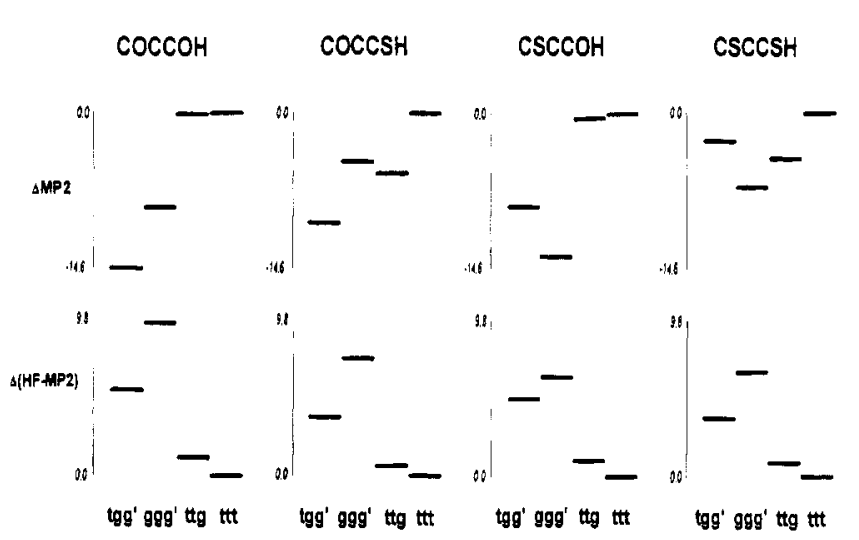

Figure 1. Conformational energy differences $\left(\times 10^{-3} E_{\mathrm{h}} ; 1 E_{\mathrm{h}}=2625.5\right.$ $\mathrm{kJ} \mathrm{mol}{ }^{-1}$ ) between $\operatorname{tgg}^{\prime}, \mathrm{ggg}^{\prime}$, ttg, and ttt conformers of $\mathrm{CH}_{3} \mathrm{XCH}_{2} \mathrm{CH}_{2^{-}}$ $\mathrm{YH}(\mathrm{X}, \mathrm{Y}=\mathrm{O}, \mathrm{S}) . \mathrm{MP} 2$ and HF-MP2 stand for the MP2/6-31G* energy and correlation correction with respect to the $6-31 G^{*}$ energy value, respectively.

\section{Results and Discussion}

Energies and Structures. Figure 1 presents conformational energy differences and correlation corrections obtained at the MP2/6-31G* level of calculation with respect to 6-31G* energy values, for the $\mathrm{tgg}^{\prime}, \mathrm{ggg}^{\prime}, \mathrm{ttg}$, and ttt conformers of $\mathrm{CH}_{3} \mathrm{XCH}_{2-}$ $\mathrm{CH}_{2} \mathrm{YH}(\mathrm{X}, \mathrm{Y}=\mathrm{O}, \mathrm{S})$. The following important conclusions can be drawn from this figure:

(i) Starting with the $\operatorname{tgg}^{\prime}$ and $g^{\prime} g^{\prime}$ conformers which are intramolecularly hydrogen bonded in 2-methoxyethanol, ${ }^{\prime}$ it is found that, for ether molecules ( $X=0), \operatorname{tgg}^{\prime}$ is more stable than $\mathrm{ggg}^{\prime}$, whereas $\mathrm{ggg}^{\prime}$ is more stable than tgg' for thioether molecules $(X=S)$. The absolute values of the $g^{\prime} g^{\prime}-\operatorname{tgg}^{\prime}$ energy differences are approximately equal for the molecules in each of these groups, in particular, ca. $6 \mathrm{~kJ} \mathrm{~mol}^{-1}$ for $\mathrm{X}=\mathrm{O}$ $\left(\mathrm{CH}_{3} \mathrm{OCH}_{2} \mathrm{CH}_{2} \mathrm{OH}\right.$ and $\left.\mathrm{CH}_{3} \mathrm{OCH}_{2} \mathrm{CH}_{2} \mathrm{SH}\right)$, and ca. $4 \mathrm{~kJ} \mathrm{~mol}^{-1}$ for $\mathrm{X}=\mathrm{S}\left(\mathrm{CH}_{3} \mathrm{SCH}_{2} \mathrm{CH}_{2} \mathrm{OH}\right.$ and $\left.\mathrm{CH}_{3} \mathrm{SCH}_{2} \mathrm{CH}_{2} \mathrm{SH}\right)$. By comparing the energies of the tgg' and ggg' conformers, it can be concluded that the $\mathrm{CO}-\mathrm{CC}$ skeleton stabilizes the trans form 
TABLE 1: Energy Differences and Changes in Geometrical Parameters for the tgg' and ggg' Conformers of $\mathrm{CH}_{3} \mathrm{XCH}_{2} \mathrm{CH}_{2} \mathrm{YH}$ $(\mathrm{X}, \mathrm{Y}=\mathrm{O}, \mathrm{S})(\mathrm{MP} 2 / 6-31 \mathrm{G} *$ Calculations)

\begin{tabular}{|c|c|c|c|c|c|c|c|c|}
\hline & \multicolumn{2}{|c|}{$\mathrm{COCCOH}$} & \multicolumn{2}{|c|}{ COCCSH } & \multicolumn{2}{|c|}{$\mathrm{CSCCOH}$} & \multicolumn{2}{|c|}{$\mathrm{CSCCSH}$} \\
\hline & $\operatorname{tgg}^{\prime}$ & $\mathrm{ggg}^{\prime}$ & $\operatorname{tgg}^{\prime}$ & $\mathrm{ggg}^{\prime}$ & $\operatorname{tgg}^{\prime}$ & $\mathrm{ggg}^{\prime}$ & $\operatorname{tgg}^{\prime}$ & $\mathrm{ggg}^{\prime}$ \\
\hline СХCC,ХCCY,ССYH & $173,60,-50$ & $82,54,-42$ & $184,65,-55$ & $74,59,-44$ & $211,67,-58$ & $75,61,-56$ & $190,73,-60$ & $72,67,-58$ \\
\hline$\Delta E / \mathrm{kJ} \mathrm{mol}^{-1}$ & 0.0 & 6.3 & 0.0 & 5.4 & 4.4 & 0.0 & 4.1 & 0.0 \\
\hline \multicolumn{9}{|l|}{$\Delta$ angles/deg } \\
\hline $\mathrm{CXCC}$ & $0(173)$ & $0(82)$ & 11 & -8 & 38 & -7 & 17 & -10 \\
\hline $\mathrm{XCCY}$ & $0(60)$ & $0(54)$ & 5 & 5 & 7 & 7 & 13 & 13 \\
\hline $\mathrm{CCYH}$ & $0(-50)$ & $0(-42)$ & -5 & -2 & -8 & -14 & -10 & -16 \\
\hline $\mathrm{CXC}$ & $0(112)$ & $0(113)$ & 0 & 0 & -12 & -13 & -13 & -13 \\
\hline $\mathrm{XCC}$ & $0(106)$ & $0(110)$ & 2 & 3 & 4 & 3 & 5 & 5 \\
\hline $\mathrm{CCY}$ & $0(110)$ & $0(110)$ & 3 & 2 & 2 & 2 & 4 & 5 \\
\hline $\mathrm{CYH}$ & $0(105)$ & $0(105)$ & -10 & -10 & 2 & 2 & -8 & -9 \\
\hline $\mathrm{X} \cdot \cdots \mathrm{HY}$ & $0(111)$ & $0(115)$ & -6 & -5 & 1 & -2 & -3 & -5 \\
\hline \multicolumn{9}{|l|}{$\Delta$ bond lengths/pm } \\
\hline $\mathrm{CX}$ & $0(142)$ & $0(142)$ & 0 & 0 & 39 & 39 & 39 & 39 \\
\hline $\mathrm{XC}$ & $0(142)$ & $0(143)$ & 0 & -1 & 40 & 39 & 40 & 38 \\
\hline $\mathrm{CC}$ & $0(151)$ & $0(152)$ & 0 & 0 & 1 & 0 & 2 & 1 \\
\hline $\mathrm{CY}$ & $0(142)$ & $0(142)$ & 40 & 40 & 0 & 0 & 40 & 40 \\
\hline YH & $0(97)$ & $0(98)$ & 37 & 36 & 0 & 0 & 38 & 36 \\
\hline $\mathrm{X} \cdot \cdot \mathrm{H}(\mathrm{Y})$ & $0(225)$ & $0(222)$ & 26 & 22 & 43 & 43 & 60 & 64 \\
\hline \multicolumn{9}{|l|}{$\Delta$ charges $/ e$} \\
\hline $\mathrm{C}$ & $0.0(-0.2)$ & $0.0(-0.2)$ & 0.0 & 0.0 & -0.4 & -0.4 & -0.4 & -0.4 \\
\hline $\mathrm{X}$ & $0.0(-0.6)$ & $0.0(-0.6)$ & 0.0 & 0.0 & 0.7 & 0.7 & 0.7 & 0.7 \\
\hline $\mathrm{C}$ & $0.0(0.0)$ & $0.0(0.0)$ & 0.0 & 0.0 & -0.5 & -0.5 & -0.5 & -0.5 \\
\hline $\mathrm{C}$ & $0.0(0.0)$ & $0.0(0.0)$ & -0.5 & -0.5 & 0.0 & 0.0 & -0.5 & -0.5 \\
\hline $\mathrm{Y}$ & $0.0(-0.8)$ & $0.0(-0.8)$ & 0.7 & 0.7 & 0.0 & 0.0 & 0.7 & 0.7 \\
\hline $\mathrm{H}$ & $0.0(0.5)$ & $0.0(0.5)$ & -0.4 & -0.4 & 0.0 & 0.0 & -0.4 & -0.4 \\
\hline
\end{tabular}

with respect to the gauche form, whereas the CS-CC axis originates a gauche form more stable than the corresponding trans form.

(ii) Passing now to the ttg and ttt forms, ttg is more stable than $\mathrm{ttt}$ for all the studied molecules. However, for $\mathrm{YH}=\mathrm{OH}$, the $\mathrm{ttt}-\mathrm{ttg}$ energy differences are smaller than $0.4 \mathrm{~kJ} \mathrm{~mol}^{-1}$, whereas for $\mathrm{YH}=\mathrm{SH}$, these differences are 5.3 and $4.0 \mathrm{~kJ}$ $\mathrm{mol}^{-1}$, for $\mathrm{X}=\mathrm{O}$ and $\mathrm{X}=\mathrm{S}$, respectively. The increased relative stability of the ttg conformer in the latter molecules makes this conformer the second more stable among the four considered conformers. The ttg vs ttt energy comparisons lead to the general conclusion that the $\mathrm{CC}-\mathrm{OH}$ axis stabilizes only slightly the gauche form with respect to the trans form, whereas the $\mathrm{CC}-\mathrm{SH}$ axis gives rise to a gauche form far more stable than the corresponding trans conformation.

(iii) The stabilizing effect of correlation as measured by $\Delta$ (HF-MP2) increases along the $\mathrm{ttt}^{2}<\mathrm{tg}<\mathrm{tgg}^{\prime}<\mathrm{ggg}^{\prime}$ series of conformers, i.e., with the number of gauche arrangements. Intuitively, this suggests that the effect of electrons avoiding each other is less important for trans arrangements than for gauche arrangements, i.e., is larger for folded conformations than stretched ones. ${ }^{5}$

(iv) If the oxygen-by-sulfur substitution effect is considered for the tgg' and ggg' $^{\prime}$ conformers, then it is concluded that the stabilizing effect of correlation is less important for thioethers $(X=S)$ than for their ether counterparts $(X=O)$.

(v) On the whole, correlation corrections are of the same magnitude or in some cases even larger than conformational energy differences and change appreciably with conformation.

Tables 1 and 2 present changes in dihedral angles, bond angles, bond lengths, contact distances, and angles, and Mulliken charges, for the $\left(\mathrm{tgg}^{\prime}, \mathrm{ggg}^{\prime}\right)$ and $(\mathrm{ttg}, \mathrm{ttt})$ pairs of conformers, respectively. The latter pair (ttg, $t t t)$ is not herein discussed in detail, since it follows similar patterns of variation for oxygenby-sulfur substitutions.

In general, larger changes are found for structural parameters involving a substituted atom. For instance, a decrease of $12^{\circ}-$ $13^{\circ}$ in the CXC angle is observed for oxygen-by-sulfur substitution in the $\mathrm{X}$ atomic position, whereas the $\mathrm{CYH}$ angle closes by $8^{\circ}-10^{\circ}$ when $\mathrm{O}$ is replaced by $\mathrm{S}$ in the $\mathrm{YH}$ bond. In turn, the $\mathrm{XCC}$ and $\mathrm{CCY}$ angles tend to open by $3^{\circ}-5^{\circ}$, while for the tgg' and ggg' conformers, the XCC and CCY changes lead to an opening of the intramolecular ring, the closing of the $\mathrm{CYH}$ angle compensates for that, thus reducing the contact angle of the $\mathrm{X} \cdot \cdots \mathrm{HY}$ interaction.

The CX, XC, CY and YH bond lengths increase by $36-40$ $\mathrm{pm}$ and the $\mathrm{X} \cdot \mathrm{H}(\mathrm{Y})$ contact distances increase by ca. $2 \times$ $10 \mathrm{pm}$ for each oxygen-by-sulfur substitution along the series of molecules $(\mathrm{O}, \mathrm{O}) \rightarrow(\mathrm{O}, \mathrm{S}) \rightarrow(\mathrm{S}, \mathrm{O}) \rightarrow(\mathrm{S}, \mathrm{S})$. In addition, both $\mathrm{X}$ and $\mathrm{Y}$ Mulliken charges increase by ca. $0.7 e$, becoming less negative when the $O$ atom is replaced by the less electronegative $S$ atom. In turn, the $\mathrm{H}(\mathrm{Y})$ atom becomes less positive by ca. $0.4 e$ when $\mathrm{Y}=\mathrm{O}$ is substituted by $\mathrm{Y}=\mathrm{S}$, and $\mathrm{C}$ atoms become negative or more negative by $(0.4-0.5) e$ when $\mathrm{O}$ is replaced by $\mathrm{S}$ in one $\mathrm{X}$ or $\mathrm{Y}$ adjacent position.

Vibrational Frequencies. Table 3 presents $v \mathrm{YH}, \tau \mathrm{CCYH}$, and $\tau \mathrm{CXCC}$ for the $\operatorname{tgg}^{\prime}, \mathrm{ggg}^{\prime}$, ttg, and ttt conformers of $\mathrm{CH}_{3}-$ $\mathrm{XCH}_{2} \mathrm{CH}_{2} \mathrm{YH}(\mathrm{X}, \mathrm{Y}=\mathrm{O}, \mathrm{S})$. Besides having the dominant contribution of a single vibrational coordinate, these vibrations are sensitive to both conformational changes and oxygen-bysulfur substitutions. While the first of these vibrational frequencies $(\nu \mathrm{YH})$ probes the $\mathrm{X} \cdot \cdots \mathrm{HY}$ interaction, the other two ( $\tau \mathrm{CXCC}$ and $\tau \mathrm{CCYH}$ ) probe important dihedral angles, namely, $\mathrm{CX}-\mathrm{CC}$ and $\mathrm{CC}-\mathrm{YH}$.

Starting with an oxygen-by-sulfur substitution for a particular conformation, larger changes are generally observed for vibrational coordinates involving a substituted atom. For instance, an oxygen-by-sulfur substitution in the $\mathrm{YH}$ oscillator leads to a large frequency decrease of $\nu \mathrm{YH}$ for the same conformer $(940$ to $1000 \mathrm{~cm}^{-1}$ ). ${ }^{6.7}$ Besides being associated with a mass effect, this substitution is accompanied by a big increase in the $\mathrm{YH}$ bond length (see Table 1) and by a force constant reduction. In turn, the same substitution on the ether $\mathrm{O}$ atom has little effect on $v \mathrm{YH}$, as it yields a frequency decrease of a few wavenumbers.

A typical hydrogen bond is associated with a $\nu \mathrm{YH}$ frequency decrease. This effect is clearly observed for $\mathrm{OH} \cdots \mathrm{O}$, if one compares $\nu \mathrm{OH}$ for hydrogen bonded and non-hydrogen bonded 
TABLE 2: Energy Differences and Changes in Geometrical Parameters for the ttg and ttt Conformers of $\mathrm{CH}_{3} \mathrm{XCH}_{2} \mathrm{CH}_{2} \mathrm{YH}_{(\mathrm{X}} \mathrm{X}$, $\mathbf{Y}=0, \mathrm{~S})\left(\mathrm{MP2} / 6-31 \mathrm{G}^{*}\right.$ Calculations)

\begin{tabular}{|c|c|c|c|c|c|c|c|c|}
\hline & \multicolumn{2}{|c|}{$\mathrm{COCCOH}$} & \multicolumn{2}{|c|}{$\mathrm{COCCSH}$} & \multicolumn{2}{|c|}{$\mathrm{CSCCOH}$} & \multicolumn{2}{|c|}{$\mathrm{CSCCSH}$} \\
\hline & $\operatorname{ttg}$ & $\mathrm{ttt}$ & $\operatorname{ttg}$ & $\mathrm{ttt}$ & $\operatorname{tg}$ & $\mathrm{ttt}$ & $\operatorname{tg}$ & $\mathrm{ttt}$ \\
\hline $\mathrm{CXCC}, \mathrm{XCCY}, \mathrm{CCYH}$ & $182,180,72$ & $180,180,180$ & $181,179,68$ & $180,180,180$ & $181,178,70$ & $180,180,180$ & $179,178,66$ & $180,180,180$ \\
\hline$\Delta E / \mathrm{kJ} \mathrm{mol}^{-1}$ & 14.5 & 14.6 & 4.4 & 9.7 & 12.2 & 12.6 & 2.5 & 6.5 \\
\hline \multicolumn{9}{|l|}{$\Delta$ angles $/ \mathrm{deg}$} \\
\hline $\mathrm{CXCC}$ & $0(182)$ & $O(180)$ & -1 & 0 & -1 & 0 & -3 & 0 \\
\hline $\mathrm{XCCY}$ & $0(180)$ & $O(180)$ & -1 & 0 & -2 & 0 & -2 & 0 \\
\hline CCYH & $0(72)$ & $O(180)$ & -4 & 0 & -2 & 0 & -6 & 0 \\
\hline $\mathrm{CXC}$ & $0(112)$ & $0(112)$ & -1 & 0 & -13 & -14 & -14 & -14 \\
\hline $\mathrm{XCC}$ & $0(107)$ & $0(107)$ & 0 & 0 & 3 & 3 & 3 & 2 \\
\hline $\mathrm{CCY}$ & $0(111)$ & $0(106)$ & 2 & 3 & 0 & 0 & 2 & 2 \\
\hline CYH & $0(107)$ & $0(108)$ & -10 & -12 & 0 & 0 & -11 & -11 \\
\hline \multicolumn{9}{|l|}{$\Delta$ bond lengths/pm } \\
\hline CX & $0(142)$ & $0(142)$ & 0 & 0 & 39 & 39 & 39 & 39 \\
\hline $\mathrm{XC}$ & $0(142)$ & $0(142)$ & 0 & 0 & 39 & 39 & 40 & 40 \\
\hline $\mathrm{CC}$ & $0(152)$ & $0(151)$ & 0 & 1 & 0 & 1 & 0 & 1 \\
\hline$C Y$ & $0(143)$ & $0(143)$ & 41 & 39 & 0 & 0 & 39 & 40 \\
\hline YH & $0(97)$ & $0(97)$ & 37 & 37 & 0 & 0 & 37 & 37 \\
\hline \multicolumn{9}{|l|}{$\Delta$ charges/e } \\
\hline $\mathrm{C}$ & $0.0(-0.2)$ & $0.0(-0.2)$ & -0.4 & -0.4 & 0.0 & 0.0 & -0.4 & -0.4 \\
\hline$X$ & $0.0(-0.6)$ & $0.0(-0.6)$ & 0.7 & 0.7 & 0.0 & 0.0 & 0.7 & 0.7 \\
\hline $\mathrm{C}$ & $0.0(0.0)$ & $0.0(0.0)$ & -0.5 & -0.5 & 0.0 & 0.0 & -0.5 & -0.5 \\
\hline $\mathrm{C}$ & $0.0(0.0)$ & $0.0(0.0)$ & 0.0 & 0.0 & -0.5 & -0.5 & -0.5 & -0.5 \\
\hline $\mathrm{Y}$ & $0.0(-0.7)$ & $0.0(-0.8)$ & 0.0 & 0.0 & 0.6 & 0.7 & 0.7 & 0.7 \\
\hline $\mathrm{H}$ & $0.0(0.4)$ & $0.0(0.4)$ & 0.0 & 0.0 & -0.3 & -0.3 & -0.3 & -0.3 \\
\hline
\end{tabular}

${ }^{a} \Delta E=E($ conformer $)-E\left(\operatorname{tgg}^{\prime}\right)$.

TABLE 3: $v \mathrm{YH}, \tau \mathrm{CCYH}$ and $\tau \mathrm{CXCC}\left(\mathrm{cm}^{-1}\right)$ for $t g g^{\prime}, \mathrm{ggg}^{\prime}$, ttg, and tt Conformers of $\mathrm{CH}_{3} \mathrm{XCH}_{2} \mathrm{CH}_{2} \mathrm{YH}(\mathrm{X}, \mathrm{Y}=\mathrm{O}$, S)

\begin{tabular}{ccccc}
\hline & tgg' $^{\prime}$ & ggg $^{\prime}$ & ttg & ttt \\
\hline$\nu$ YH & & & & \\
O, O & 3749 & 3728 & 3775 & 3789 \\
O, S & 2800 & 2789 & 2783 & 2789 \\
S, O & 3736 & 3723 & 3773 & 3777 \\
S, S & 2792 & 2779 & 2782 & 2781 \\
$\tau$ CCYH & & & & \\
O, O & 470 & 490 & 325 & 266 \\
O, S & 300 & 297 & 230 & 143 \\
S, O & 427 & 443 & 329 & 271 \\
S, S & 234 & 267 & 235 & 161 \\
$\tau$ CXCC & & & & \\
O, O & 95 & 67 & 102 & 102 \\
O, S & 85 & 62 & 99 & 101 \\
S, O & 39 & 71 & 55 & 52 \\
S, S & 39 & 54 & 61 & 60
\end{tabular}

conformers (for example, $\nu \mathrm{OH}\left(\mathrm{tgg}^{\prime}\right)-\nu \mathrm{OH}(\mathrm{ttt}) \approx-40 \mathrm{~cm}^{-1}$ ). However, this kind of comparison should not be valid for very weak interactions, as for $\mathrm{SH} \cdot \cdots \mathrm{O}$ and $\mathrm{SH} \cdot \cdots \mathrm{S}$ interactions, for then different $\mathrm{YH} \cdots \mathrm{X}$ geometries make the comparison misleading. Moreover, the anarmonicity corrections should be taken into consideration.

Passing now to $\tau \mathrm{CCYH}$ (Table 3 ), it is found that for the $(\mathrm{O}, \mathrm{O}),(\mathrm{O}, \mathrm{S})$, and $(\mathrm{S}, \mathrm{O})$ compounds, these vibrational frequencies point out to three groups of conformers which are, by decreasing order of frequencies, (i) the pair of hydrogen bonded

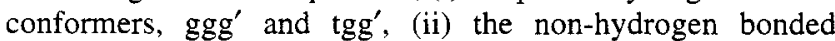
conformer gauche in the CCYH axis, ttg, and (iii) the nonhydrogen bonded conformer whose $\mathrm{CCYH}$ axis is trans, i.e., the ttt form. However, for the (S,S) compound, the distinction is rather between a CC-SH gauche arrangement $\left(\right.$ tgg $^{\prime}, \mathrm{ggg}^{\prime}$, $\mathrm{ttg}$ conformers) and a CC-SH trans axis (ttt form). In addition, for a particular (X, Y) molecule, the difference between the highest and the lowest frequencies of the conformers takes the values $224,157,172$, and $106 \mathrm{~cm}^{-1}$, for the $(\mathrm{O}, \mathrm{O}),(\mathrm{O}, \mathrm{S}),(\mathrm{S}, \mathrm{O})$, and $(\mathrm{S}, \mathrm{S})$ molecules, respectively.

Considering now tgg' and $\operatorname{ggg}^{\prime}$ with the same $\mathrm{X}$ atom, an oxygen-by-sulfur substitution in the $\mathrm{Y}$ position yields negative frequency shifts between -170 and $-193 \mathrm{~cm}^{-1}$. Instead, the same vertical comparisons in Table 3, now for the ttg and ttt conformers, yield frequency shifts between -94 and -123 $\mathrm{cm}^{-1}$. In addition, for the tgg' and $\mathrm{ggg}^{\prime}$ forms with the same $\mathrm{Y}$ atom, an oxygen-by-sulfur substitution in the ether group yields frequency shifts between -30 and $-66 \mathrm{~cm}^{-1}$. In turn, for ttg and ttt, positive frequency shifts of a few wavenumbers are observed for the same oxygen-by-sulfur substitutions. Hence, it can be generally concluded that an oxygen-by-sulfur substitution causes a larger negative shift when it occurs in the $\mathrm{YH}$ oscillator, for the intramolecularly bonded conformers, $\operatorname{tgg}^{\prime}$ and ggg'.

Finally, considering $\tau \mathrm{CXCC}$ (Table 3 ) and oxygen-by-sulfur substitutions, then it is found that these frequencies are relatively close to each other for the same $X$ atom. In turn, they show larger changes whenever $\mathrm{X}$ is replaced. In addition, with the single exception of the ggg' form, an oxygen-by-sulfur substitution in the ether group leads to a frequency decrease of ca. 40 to $50 \mathrm{~cm}^{-1}$. For $\mathrm{ggg}^{\prime}, \tau \mathrm{CXCC}$ frequency values occur in the short range $54-71 \mathrm{~cm}^{-1}$.

Comparisons of different conformers for the same compound (i.e., horizontal comparisons in Table 3), lead to the conclusion that, for the $(\mathrm{O}, \mathrm{O})$ and $(\mathrm{O}, \mathrm{S})$ molecules, the frequencies tend to group according to the type of conformational arrangement around the $\mathrm{CX}-\mathrm{CC}$ axis, i.e., one group includes frequency values for $\operatorname{tgg}^{\prime}, \operatorname{ttg}$ and ttt, the other includes $\tau \mathrm{CXCC}$ for the $\mathrm{ggg}^{\prime}$ form. When $\mathrm{X}=\mathrm{S}$, i.e., for the $(\mathrm{S}, \mathrm{O})$ and $(\mathrm{S}, \mathrm{S})$ molecules, $\tau$ CXCC values do not show a clear pattern of variation.

\section{Conclusions}

In general, the above mentioned trends of conformational energy differences, structural parameters and vibrational frequencies can be classified in two types: one is made of gradual changes which modulate the strength of the X - $\cdot \mathrm{HY}$ intramolecular interaction along the $(\mathrm{O}, \mathrm{O}) \rightarrow(\mathrm{O}, \mathrm{S}) \rightarrow(\mathrm{S}, \mathrm{O}) \rightarrow(\mathrm{S}, \mathrm{S})$ series of molecules; the other includes abrupt changes, namely those which invert the relative stability of conformers upon oxygen-by-sulfur substitution.

Energy changes associated with the strength of the $\mathrm{X} \cdot \cdots \mathrm{HY}$ intramolecular interaction and contact distances easily emerge 
from a comparison of $\operatorname{tgg}^{\prime}$ and all-trans conformers. In particular, along the above series of molecules, the $t \mathrm{tt}-\mathrm{tgg}^{\prime}$ energy difference diminishes gradually and, for the tgg' and ggg' conformers, the $\mathrm{X} \cdot \cdots \mathrm{H}(\mathrm{Y})$ contact distance increases monotonically, suggesting a less stabilizing effect of the intramolecular interaction along that series of molecules.

Changes of the second kind are found, for example, when the relative stability of tgg' $^{\prime}$ and ggg' conformers upon oxygenby-sulfur substitution is considered. In fact, for $X=O$, tgg' $^{\prime}$ is more stable than $\mathrm{ggg}^{\prime}$, whereas for $\mathrm{X}=\mathrm{S}$, $\mathrm{ggg}^{\prime}$ is more stable than $\operatorname{tgg}^{\prime}$. In addition, while ttg is more stable than ttt for all the studied molecules, these differences are small and negligible when $\mathrm{Y}=\mathrm{O}$, and appreciable and almost equal when $\mathrm{Y}=\mathrm{S}$. On the whole, oxygen-by-sulfur substitutions in the central bonds of the dihedral angles $\mathrm{CX}-\mathrm{CC}$ and $\mathrm{CC}-\mathrm{YH}$ favor gauche over trans conformations.

Acknowledgment. The authors thank JNICT (Junta Nacional de Investigação Científica), Lisboa, for pluriannual financial support of the Molecular Physical Chemistry Research Group where this research has been accomplished, and F.P.S.C. thanks the Education Ministry for a SEAD-PRODEP research grant.

\section{References and Notes}

(1) Gil, F. P. S. C.; Fausto, R.; Amorim da Costa, A. M.; TeixeiraDias, J. J. C. J. Chem. Soc., Faraday Trans. 1994, 90, 689

(2) Gil, F. P. S. C.; Amorim da Costa, A. M.; Bruns, R. E.; TeixeiraDias, J. J. C. J. Phys. Chem., 99, 634, 1995.

(3) Gil, F. P. S. C.; Amorim da Costa, A. M.; Teixeira-Dias, J. J. C. J. Phys. Chem. 1995, 99, 8066.

(4) Frisch, M. J.; Trucks, G. W.; Head-Gordon, M.: Gill, P. M. W.; Wong, M. W.; Foresman, J. B.; Johnson, B. G.; Schlegel, H. B.: Robb, M. A.; Replogle, E. S.; Gomperts, R.; Anders, J. L.: Raghavachari, K.; Binkley, J. S.; Gonzalez, C.: Martin, R. L.; Fox, D. J.; Defrees, D. J.; Baker, J. Stewart, J. J. P.; Pople, J. A. Gaussian 92, revision A; Gaussian Inc., Pittsburgh, PA, 1992.

(5) Frey, R. F.; Cao, M.; Newton, S. Q.; Schäfer, L. J. Mol. Struct. (THEOCHEM) 1993, 285, 99

(6) Tichy, M. In Advances in Organic Chemistry-Methods and Results; Interscience: New York, 1965, Vol. 5, pp 115-298.

(7) Zeegers-Huyskens, Th. In Intermolecular forces: an introduction to modern methods and results; Huyskens, P. L.; Luck, W. A. P.: ZeegersHuyskens, T., Eds.; Springer-Verlag Berlin, 1991; pp 123-155.

JP951525U 